\title{
Toxicity of Cypermethrin-chlorpyrifos and Butachlor to Tadpole of Quasipaa boulengeri
}

\author{
Zhang Xiaoqin $^{1 *}$, Zhao Changju ${ }^{1}$, and Wu Haoyang ${ }^{1}$ \\ ${ }^{1}$ College of Resources and Environment, A’Ba Teachers University, Wenchuan, Sichuan Province 623002, China.
}

\begin{abstract}
The tadpole of Quasipaa boulangeri was taken as the research object in this paper. The toxic effects of cypermethrin-chlorpyrifos and butachlor on tadpole of Q.boulangeri were studied by acute toxicity experiment and subchronic toxicity experiment in order to master the toxicity of different types of pesticides on tadpole of Q.boulangeri and provide scientific basis for amphibian protection. The results of acute toxicity experiment were analyzed by the method of probability unit regression analysis. The results of the acute toxicity experiment were analyzed by means of the probability-unit regression analysis method, and the $\mathrm{LC}_{50}$ of cypermethrin-chlorpyrifos and butachlor to the 2-month-old frog tadpoles at $24 \mathrm{~h}, 48 \mathrm{~h}, 72 \mathrm{~h}$ and $96 \mathrm{~h}$ were $0.419,0.357,0.346 \mathrm{~L}, 0.332$ and $1.183,1.108,0.925$ and $0.876(\mathrm{mg} / \mathrm{L})$, respectively. In the subchronic toxicity experiment, we observed the accumulation effect of different concentrations of pesticides on tadpoles through the statistics of the growth and development of tadpoles exposed to the drugs for a long time. The results suggested that the body length and body weight of tadpoles increased slowly with the increase of time and concentration of pesticide in the solution during the experiment.
\end{abstract}

\section{Introduction}

With the continuous development of agriculture, the use of a large number of pesticides has not only caused serious pollution to the natural environment, especially water resources, but also had a certain impact on the growth and development of aquatic organisms and amphibians. Some studies have proved that the decline of amphibian population is closely related to pesticide pollution $^{[1]}$. Liu Ying's experimental results showed that six pesticides, including triazophos, chlorpyrifos, acetochlor and butachlor, had high toxicity to Microhyla pulchra and tadpole of Bufo Melanostictus Schneider ${ }^{[2]}$. He Zhigang's study on the use of pesticides in paddy fields in the living environment of Pelophylax nigromaculatus showed that pesticides had some effects on the growth and development, tissue structure and genetic material of tadpoles $^{[3]}$. Geng studied the effects of dichlorvos and butachlor on four species of batrachians through acute toxicity experiments. It was found that there were great differences in the sensitivity of different species of tadpoles to pesticides ${ }^{[4]}$. Howe exposed Lithobates pipiens to herbicides and found that herbicides cause deformities of tadpoles' tails, tissues and organs ${ }^{[5]}$. Quasipaa boulengeri, which a rare amphibian endemic to China, is commonly known as stone frog, Bangbang fish and so on and named Paa tibetanus ${ }^{[6]}$. This paper mainly studies the acute toxic effects of common pesticide cypermethrin-chlorpyrifos and herbicide butachlor on Q.boulangeri tadpoles and the subchronic toxicity effects of herbicide butachlor on Q.boulangeri tadpoles. It not only provides a scientific basis for the protection of wild Q.boulangeri tadpoles, but also has a positive impact on environmental protection.

\section{Material and Methods}

\subsection{Reagent}

The pesticides used in the experiment were chlorpyrifos chlorpyrifos with 50 percent total active component of emulsion, including chlorpyrifos 45 percentand cypermethrin 5 percent, which were produced by Jiangsu Lanfeng Bio-Chemical Co.,Ltd. The other, butachlor, is made by Jiangsu Lvilai Co., Ltd., which has an active ingredient of 60 percent dairy oil.

\subsection{Animals}

The tadpoles selected in this experiment were purchased from the professional cooperative of Q.boulangeri breeding in Linxidi, Ya'an City. The tadpole is the completion stage of 25 Gill cover fold ${ }^{[7]}$.

\footnotetext{
* Corresponding author: qingerzx1982@163.com
} 


\section{Acute toxicity of cypermethrin- chlorpyrifos and butachlor to Q.boulangeri tadpoles}

\subsection{Preliminary test}

During the experiment, the water temperature was maintained at $22-25^{\circ} \mathrm{C}$ and the tadpoles were fed in a circular basin and stopped feeding 24 hours before the start of the experiment. Four concentration gradient experimental groups and one blank group were set up, and 10 tadpoles of Q.boulangeri were placed in each concentration group. The experiment lasted for 96 hours, and the 24-hour total death concentration $\left(\mathrm{LC}_{100}\right)$ and 96-hour non-death concentration $\left(\mathrm{LC}_{0}\right)$ of the two reagents were selected respectively.

\subsection{Acute toxicity test}

This experiment adopts the method of semi-purified water biological test ${ }^{[8]}$. The test solution was changed every 24 hours during the experiment. Five concentration gradient groups and one blank group were set up. The cypermethrin-chlorpyrifos group was treated with $0.15, \quad 0.30, \quad 0.45, \quad 0.60, \quad 0.75 \mathrm{mg} / \mathrm{L}$ respectively, and the butachlor test concentration was $0.198,0.948,1.700,2.300,3.084 \mathrm{mg} / \mathrm{L}$. Ten tadpoles of uniform size, healthy and active were put into each group and were not fed during the experiment. The death number of tadpoles of Q.boulangeri were recorded at $24 \mathrm{~h}, 48 \mathrm{~h}, 72 \mathrm{~h}$ and $96 \mathrm{~h}$ after the beginning of the experiment. The death standard was that there was no blood supply to the heart of tadpoles. The poisoning symptoms of tadpoles were recorded and the dead individuals were cleaned up in time.

\subsection{Results and analysis of acute toxicity test}

\subsubsection{Poisoning symptoms}

No dead individuals were found in the tadpoles of Q.boulangeri in the blank group and the activity performance was normal during the experiment. The tadpoles of the Q.boulangeri do irregular strenuous exercise after a few seconds of contact with venom. After a period of time, it was observed that the excrement of the high concentration group was more than that of the low concentration group, and the tadpoles showed a certain adaptability mostly resting at the bottom of the water and some turn over or ventral side up at the bottom of the basin. The death of Q.boulangeri tadpoles in the two test solutions were accompanied by liver enlargement and some of the tadpoles in the butachlor group showed tail bending deformity. The tail of the dead tadpoles in the cypermethrin-chlorpyrifos group showed varying degrees of internal bleeding in the figure 1, while in the butachlor group, there was more slight bleeding in the liver as shown in figure 2.
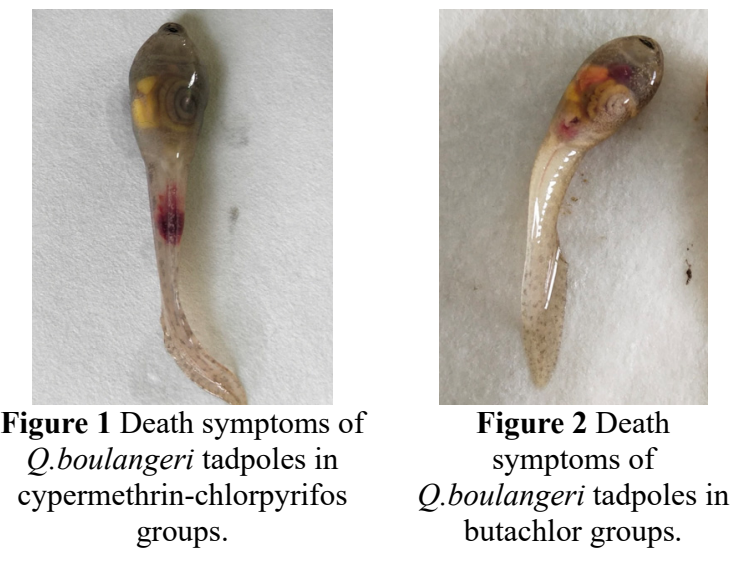

\subsubsection{Result analysis}

The death of tadpoles of cypermethrin-chlorpyrifos in each treatment group was shown in Table 1 after 96 hours of exposure. Probit probability unit regression analysis ${ }^{[9]}$ was used to analyze the drug concentration of cypermethrin-chlorpyrifos, butachlor and the cumulative death number of tadpoles. The results obtained by probability unit method were used to find the semi-lethal concentrations of cypermethrinchlorpyrifos, butachlor to Q.boulangeri tadpoles for $24 \mathrm{~h}, 48 \mathrm{~h}, 72 \mathrm{~h}, 96 \mathrm{~h}$ and the safe concentrations were calculated. The results are shown in Table 2. The safe concentration $(\mathrm{SC})=0.1 \times \mathrm{LC}_{50}(96 \mathrm{~h})$.

Table 1 and Table 2 showed that the safe concentrations of Q.boulangeri tadpoles treated with cypermethrin-chlorpyrifos and butachlor were 0.0332 $\mathrm{mg} / \mathrm{L}$ and $0.0876 \mathrm{mg} / \mathrm{L}$, respectively. The $\mathrm{LC}_{50}$ value decreased with the extension of the experimental time and the toxic ability gradually increased with the increase of exposure time. The toxicity grade is divided into four grades: $\mathrm{LC}_{50} \leq 0.1$ as virulent toxicity grade, $0.1<\mathrm{LC}_{50} \leq 1.0$ as high toxicity grade, $1.0<\mathrm{LC}_{50} \leq 10$ as medium toxicity grade, $\mathrm{LC}_{50}>10$ as low toxicity grade according to the $96 \mathrm{~h}-\mathrm{LC}_{50}(\mathrm{mg} / \mathrm{L})$ standard of pesticides to fish in the environmental safety assessment test criteria of chemical pesticides in China $^{[10]}$, the cypermethrin-chlorpyrifos and butachlor are highly toxic pesticides to Q.boulangeri tadpoles.

Table 1 Acute toxicity results of cypermethrin-chlorpyrifos and butachlor Q.boulangeri tadpoles.

\begin{tabular}{lcccccc}
\hline Pesticide & $\begin{array}{c}\text { Concent } \\
\text { ration }\end{array}$ & $\begin{array}{c}\text { The total } \\
\text { number of } \\
\text { tadpoles }\end{array}$ & \multicolumn{3}{c}{$\begin{array}{c}\text { Accumulated number } \\
\text { of dead tadpoles }\end{array}$} \\
mg/L & number & $\begin{array}{c}24 \\
\text { h }\end{array}$ & $\begin{array}{c}48 \\
\text { h }\end{array}$ & $\begin{array}{c}72 \\
\text { h }\end{array}$ & h \\
\hline blank control & 0 & 20 & 0 & 0 & 0 & 0 \\
group & & & & & & \\
cypermethrin & 0.30 & 20 & 0 & 0 & 0 & 0 \\
-chlorpyrifos & 0.45 & 20 & 5 & 6 & 6 & 8 \\
& 0.60 & 20 & 14 & 18 & 18 & 18 \\
& 0.75 & 20 & 19 & 19 & 20 & 20 \\
butachlor & 0.198 & 20 & 0 & 0 & 0 & 0 \\
& 0.948 & 20 & 3 & 11 & 14 & 14 \\
& 1.700 & 20 & 13 & 17 & 18 & 19 \\
& 2.300 & 20 & 14 & 19 & 20 & 20 \\
& 3.084 & 20 & 17 & 20 & 20 & 20 \\
\hline
\end{tabular}


Table 2 Regression analysis of acute toxicity of cypermethrin-chlorpyrifos and butachlor to Q.boulangeri tadpoles.

\begin{tabular}{cllll}
\hline Pesticide & $\begin{array}{l}\text { Time } \\
(\mathrm{h})\end{array}$ & $\begin{array}{l}\text { Regression equati- } \\
\text { on }\end{array}$ & $\begin{array}{l}\text { Significance } \\
(p \text { value })\end{array}$ & $\begin{array}{l}\text { Medium let- } \\
\text { hal concentr } \\
\text { ation(mg/L) }\end{array}$ \\
\hline cypermet & 24 & $\mathrm{p}=-2.633+6.289 \mathrm{x}$ & 0.479 & 0.419 \\
hrin- & 48 & $\mathrm{p}=-3.414+9.562 \mathrm{x}$ & 0.320 & 0.357 \\
chlorpyri & 72 & $\mathrm{p}=-.449+12.875 \mathrm{x}$ & 0.995 & 0.346 \\
fos & 96 & $\mathrm{p}=-.971+11.966 \mathrm{x}$ & 0.958 & 0.332 \\
& 24 & $\mathrm{p}=-2.050+1.131 \mathrm{x}$ & 0.197 & 1.183 \\
butachlor & 48 & $\mathrm{p}=-2.013+1.816 \mathrm{x}$ & 0.248 & 1.108 \\
& 72 & $\mathrm{p}=-2.168+2.345 \mathrm{x}$ & 0.174 & 0.925 \\
& 96 & $\mathrm{p}=-2.407+2.747 \mathrm{x}$ & 0.340 & 0.876 \\
\hline
\end{tabular}

Note: P. Unit of probability of death; X. Logarithm of concentration of experimental agents. Pearson goodness of fit significance $P>0.05$, indicating that the model can fit the experimental data well.

\section{Subchronic toxicity of butachlor to Q.boulengeri tadpoles}

\subsection{Subchronic toxicity test}

The concentrations of each group were $0.1,0.2,0.3$ and $0.4 \mathrm{mg} / \mathrm{L}$, respectively. Each group was divided into 3 parallel groups and corresponding control groups. 15 tadpoles of Q.boulangeri with uniform size, health and strong mobility were placed in each group.

\subsection{Experimental results and analysis of subchronic toxicity}

The results of two-way without repetitive analysis of variance of the average body length and body weight of the tadpoles exposed to butachlor for $0 \mathrm{~d}, 5 \mathrm{~d}, 10 \mathrm{~d}$, $15 \mathrm{~d}$ and $20 \mathrm{~d}$ and the control group were shown in Table 3 and the results of one-way ANOVA were shown in Figure 3 and Figure 4. In the subchronic toxicity experiment, the average \pm standard deviation method was used to represent the body length and body weight of the tadpoles. One-way analysis of variance (One-way ANOVA) was used to compare the changes of the data of each experimental group in each time period, and the two-way analysis of variance was used to analyze all the data and significant level $\alpha=0.05$. The data were processed by SPSS 25.0 software. It can be seen from Table 3 that there is a significant difference in time on the body length and weight of Q.boulangeri tadpoles at 0.05 level, but there is no significant difference in concentration on the body length of Q.boulangeri tadpoles. It can be seen from Figure 3 and Figure 4 that the body weight of Q.boulangeri tadpoles increases slowly with the increase of pesticide concentration in the test solution.

In summary, it can be concluded that during the experiment, with the extension of exposure time and the increase of pesticide concentration in the test solution, the inhibition on the growth of body length and body weight of Q.boulangeri tadpoles was more obvious.
Table 3 The test results of main effect of butachlor concentrationand time on body length and weight of Q.boulangeri tadpole

\begin{tabular}{lllllll}
\hline & \multicolumn{5}{c}{ Intersubjective effect test } \\
& & Degree of & Mean & & Significance \\
Variable & Source & freedom & square & $F$ & $(p$ value $)$ \\
\hline \multirow{2}{*}{ length } & time & 4 & 0.541 & 6.204 & $0.000^{* *}$ \\
& concentration & 4 & 0.113 & 1.300 & 0.269 \\
weight & time & 4 & 0.031 & 3.659 & $0.006^{*}$ \\
& concentration & 4 & 0.030 & 3.597 & $0.007^{*}$ \\
\hline
\end{tabular}

Note: $P<0.05$ indicates significant difference.

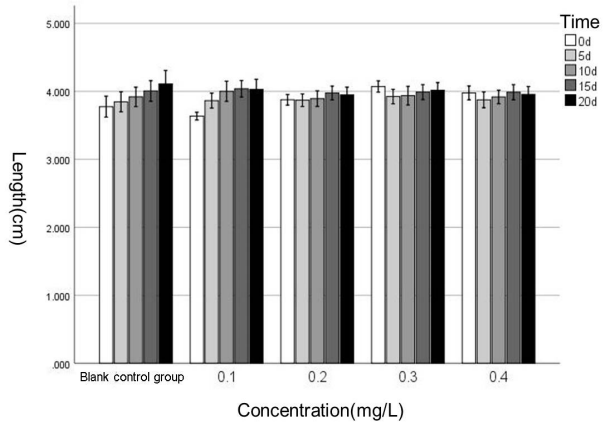

Figure 3 Variation of body length of Q.boulangeri tadpoles with different concentrations of butachlor in 20 days.

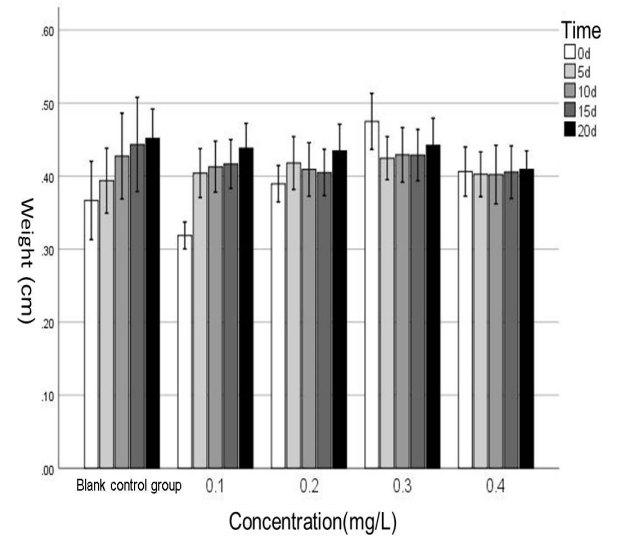

Figure 4 Changes of body weightof $Q$. boulangeri tadpoles with different concentrations of butachlor in 20 days.

\section{Conclusion}

The results of acute toxicity test showed that cypermethrin-chlorpyrifos and butachlor were highly toxic pesticides to Q.boulangeri tadpoles. The results of subchronic toxicity test showed that low concentration of butachlor test solution could promote the growth of body length and body weight of Q.boulangeri tadpoles in a short time, while high concentration of butachlor test solution could inhibit the growth of body length and body weight of Q.boulangeri tadpoles. The higher the concentration of pesticide, the more obvious the inhibitory effect. 
In summary, it can be seen that the effects of pesticides on amphibian tadpoles are not only shown in the short-term acute toxic effects, but also have potential effects on the growth and development of tadpoles with long-term low concentrations of pesticides. Therefore, the application of pesticides in agriculture should be strictly controlled to avoid the toxic effects of pesticides on amphibians and other aquatic organisms. It also urges people to scientifically and standardize the use of pesticides in daily production practice to minimize the impact on the environment and aquatic organisms.

\section{Acknowledgements}

This work was supported by the grants from project of A'ba Normal University (No. ASA21-06) to Xiaoqin Zhang and from project of A'ba Normal University (No.ASC20-04) to Xuemei Xian.

\section{References}

1. Cheek AO, Bollinger JE and Pider CV (1999) Alteration of Leopard Frog (Rana pipiens) Metamorphosis by the Herbicide Acetochlor $J$. Archive of Envionmental Contamination Toxicology.37 pp 70-7.

2. Ying L, Yan H and Lei J (2015) Acute Toxicity of Six Pesticides Used in Rice Field on Tadpole of Microhyla pulchra and Bufo melanostictus $J$. Agrochemicals.54(11) pp 825-7.

3. Zhigang H, Yuanan W, Dongwu W, Yongfu X, Jinglong $L$ and Ming $Z$ (2018) Effects of pesticides on the toxicity of Pelophylax nigromaculatus in Paddy Field J. Grain Oil And Feed Technology.(02) pp 27-31.

4. Geng BR, Yao D, Xue QQ (2005) Genotoxicity of the pesticide dichlorvos and herbicide butachlor in Rhacophorus megacephaslus tasdpoles J. Acta Zoologica Sinca.51(3) pp 447-454.

5. Howe C, Berrili M and Pauli D (2008) The Acute and Chronic Toxicity of Glyphosate-Based Pesticides in Northern Leopard Frogs $J$. Methods.(2008) 1-7.

6. Shibo X, Jingming X, Fan Y, Hong C, Zhen W and Chuan X (2020) Research Progress on the Biological Characteristics and Resource Conservation of Quasipaa boulengeri J. Chinese Journal of Zoology.55(01) pp 105-9.

7. Ermi Z (1990) Introduction of a frog embryo and Stages of tadpole development $J$. Bulletin of Biology.(01) pp 13-5.

8. Yongxin Z and Zongshe Z (1989) Test method for toxicity of aquatic organisms $M$. China Agriculture Press. pp 5-143.

9. Cuiping L, Minyao W and Hongyuan W (2012) $\mathrm{LC}_{50}$ Caculated by Kochi, Probit Analysis and
Linear Regression Methods J. Progress in Veterinary Medicine.33(09) pp 89-92.

10. (2004) Test criteria for environmental safety assessment of chemical pesticides $R$. The ministry of agriculture of the People's Republic of China.GB\#\#-2004. 